\title{
Influência do traçado e malha nos custos de implantação de loteamentos horizontais urbanos: uma revisão sistemática
}

\author{
Influence of layout and mesh on the implementation costs of urban \\ horizontal subdivisions: A systematic review
}

\author{
${ }^{1}$ Maria Laura Cavalari Faeda \\ ${ }^{2}$ Ivan Julio Apolonio Callejas \\ ${ }^{1}$ Engenheira Civil pela Universidade Federal de Mato Grosso \\ (marialaurafaeda@gmail.com) \\ ${ }^{2}$ Docente do Departamento de Arquitetura e Urbanismo - Universidade Federal de Mato Grosso \\ (ivancallejas@ufmt.br)
}

\begin{abstract}
RESUMO: Com o crescimento das cidades observado nas últimas décadas, a demanda pelos sistemas de infraestrutura básica também tem aumentado. Diante disso, surge o questionamento acerca de como a escolha do traçado e malha influência nos custos de implantação de loteamentos horizontais urbanos. O presente trabalho objetiva identificar a influência do traçado e malha nos custos de implantação de loteamentos horizontais urbanos através da utilização da estratégia de revisão sistemática. Por meio dessa técnica, procedeu-se a coleta e síntese de trabalhos relevantes sobre tema pesquisado com vistas a identificar quais os principais indicadores utilizados para diagnóstico de diferentes concepções urbanísticas (traçado e malha urbana) e sua influência/indução nos custos de infraestrutura das glebas urbanizadas. Observou-se que as pesquisas possuem pontos convergentes em relação à influência do traçado e malha viária nos custos de infraestrutura, com o indicador de porcentagem de malha viário sendo um dos principais fatores que influenciam a elevação dos custos, visto que os demais subsistemas de infraestrutura, em geral, guardam estreita relação com o traçado definido para as vias a serem pavimentadas. Foi possível concluir que a escolha do traçado viário é um importante fator que influencia os custos de infraestrutura.
\end{abstract}

Palavras Chave: Loteamentos horizontais. Custos. Urbanização. Indicadores físicos. Malha urbana. Traçado viário.

\begin{abstract}
With the growth of cities observed in recent decades, the demand for basic infrastructure systems has also increased. Therefore, the question arises about how the choice of layout and mesh influences the costs of implementing urban horizontal subdivisions. The present work aims to identify the influence of the layout and mesh on the implementation costs of urban horizontal subdivisions through the use of the systematic review strategy. Through this technique, the collection and synthesis of relevant works on the researched topic was carried out to identify the main indicators used to diagnose different urban concepts (urban layout and mesh) and their influence/induction on the infrastructure costs of the plots urbanized. It was observed that the surveys have converging points concerning the influence of the layout and road network on infrastructure costs, with the percentage of road network indicator being one of the main factors influencing the rise in costs, as the other infrastructure subsystems, in general, are closely related to the route defined for the roads to be paved. It was possible to conclude that the choice of road layout is an important factor influencing infrastructure costs.
\end{abstract}

Keywords: Horizontal subdivisions. Costs. Urbanization. Physical indicators. Urban mesh. Road layout.

\section{INTRODUÇÃO}

Zmitrowicz e Neto (1997) definem infraestrutura urbana como o conjunto de sistemas técnicos e serviços necessários para o desenvolvimento urbano, cuja função pode ser vista sob o ponto de vista social, econômico e institucional. Em relação ao primeiro, almeja-se promover adequadas condições de moradia, trabalho, saúde, educação, lazer e segurança. Quanto ao segundo, intenciona-se proporcionar adequadas condições para o desenvolvimento das atividades produtivas. E finalmente quanto ao terceiro, busca-se os meios necessários ao desenvolvimento das atividades político-administrativas. Nesse contexto, são todos os elementos e serviços que proporcionam adequada habitabilidade e qualidade de vida para a população dentro das cidades, de tal forma que ela possa viver dignamente. 
O Brasil tem passado por um intenso processo de urbanização, com necessidade de crescentes investimentos públicos com vistas a prover as cidades com adequados serviços e sistemas de infraestrutura urbana. Além disso, o atendimento quanto aos requisitos de sustentabilidade impõe a necessidade de que estes sistemas sejam projetados e implementados de forma harmônica com o meio ambiente, preservando o máximo possível o ambiente natural, articulando-se ainda com o espaço urbano em seu entorno. Como alternativa, vislumbra-se a idealização de bairros e conjuntos habitacionais que busquem a qualidade do ambiente construído a partir de critérios ambientais e sociais pré-estabelecidos nas legislações e normas, ao mesmo tempo em que se procura minimizar custos de urbanização e das edificações. Esse enfoque permite desenvolver uma urbanização mais acessível e eficaz, com melhor aproveitamento dos recursos, sejam eles públicos ou privados.

A Lei 6.766 (BRASIL, 1979), que dispõe sobre o Parcelamento do Solo Urbano, estabelece que a infraestrutura básica dos parcelamentos situados nas zonas habitacionais declaradas por lei como zona de interesse social, constitui-se de no mínimo de equipamentos urbanos de escoamento das águas pluviais, iluminação pública, esgotamento sanitário, abastecimento de água potável, energia elétrica pública e domiciliar e vias de circulação. No entanto, como o desenvolvimento urbano de cada cidade é dependente de suas características geográficas e de suas potencialidades econômicas, bem como da sua situação política e social (CASTELNOU, 2007), é inegável que estes subsistemas no atual estágio de desenvolvimento da sociedade brasileira não são suficientes para garantia da adequada qualidade de vida da população nas cidades. Nesse caminho, pode-se citar também os subsistemas de telecomunicações e de mobilidade urbana como fundamentais para proporcionar a saúde e bem-estar das pessoas que residem no ambiente urbano.

Embora se saiba que todos os subsistemas de infraestrutura urbana impactam o processo de urbanização, o traçado e a malha urbana projetada para os loteamentos habitacionais têm forte impacto e importância nos custos de infraestrutura urbana. Alguns estudos, como Andrade (1983), Inouye e Souza (2004) Inouye (2009) e Eloy e Cardoso (2011), têm indicado que a escolha do traçado e malha viário se constitui em uma das principais etapas do projeto urbanístico que influencia os custos de infraestrutura. Ainda, apontam que a porcentagem de malha viária é um dos fatores mais influenciadores da elevação dos custos, visto que os demais componentes dos subsistemas, em geral, acompanham o desenho urbanístico proposto para a gleba/ loteamento. Nesse sentido, pesquisas se proponham a aprofundar esse tema são de fundamental importância para embasar e munir a sociedade de conhecimento técnico-científico com vistas ao desenvolvimento de estratégias para o planejamento urbanístico das cidades, a partir dos aspectos socioeconômicos e ambientais, fundamentais para a garantia da sustentabilidade urbana.

Nesse sentido, este trabalho procura contribuir para o planejamento urbano sob o ponto de vista socioeconômico, por meio de uma analise da produção técnico-científica que considere a influência do traçado e malha viária nos custos de implantação das obras de infraestrutura urbana. Busca-se identificar os impactos que estas decisões urbanísticas trazem para implantação de loteamentos horizontais urbanos. Assim, objetiva-se analisar a influência da escolha do traçado e malha viária nos custos de implantação de loteamentos horizontais urbanos, bem como identificar quais as tipologias que acarretam menores custos de urbanização e melhor aproveitamento da gleba urbanizada. Além disso, busca-se realizar um levantamento dos indicadores urbanísticos que influenciam diretamente no aumento dos custos orçamentários. 


\section{MATERIAIS E MÉTODOS}

Este trabalho se utiliza da técnica de revisão sistemática que se caracteriza como um instrumento de investigação científica, na qual são reunidas pesquisas relevantes sobre uma determinada questão previamente formulada. Utiliza-se de banco de dados da literatura como fonte de pesquisa para identificação, seleção e análise sistemática, com intuito de se realizar uma revisão crítica e abrangente da literatura sobre um determinado tema pesquisado. Nesse sentido, dispõe de uma metodologia adequada e atual para reunir um conjunto de evidências concatenadas a uma estratégia de intervenção específica, por intermédio da aplicação de métodos explícitos e sistematizados de busca, apreciação crítica e síntese da informação selecionada.

Essa metodologia tem como objetivo promover a interação de informações de estudos que foram conduzidos de forma individualizada sobre determinada terapêutica/intervenção, que podem apresentar resultados coincidentes, ou ainda conflitantes, bem como podem apontar temáticas que necessitam de evidências, contribuindo na orientação para indagações futuras (SAMPAIO E MANCINI, 2006; DE SOUSA E RIBEIRO, 2009). No presente estudo, a revisão sistemática foi conduzida com intuito de responder ao seguinte questionamento: Quais os custos inerentes a implantação de cada subsistema de infraestrutura? Quais indicadores têm sido utilizados para quantificar a influência do traçado e malha nos custos de infraestrutura urbana de loteamentos horizontais?

Para o desenvolvimento da revisão sistemática, utilizou-se como fonte de dados artigos científicos e dissertações oriundos de bancos de dados disponíveis em portais online, como CAPES, Scielo e Google Acadêmico, com enfoque na produção nacional sobre o tema. Para a busca, optou-se pelos seguintes descritores: "custos", "urbanização", "forma urbana". Devido à escassez de produção científica sobre a temática, não se procedeu delimitação temporal nas bases de dados pesquisadas.

As publicações foram pré-selecionadas por meio da leitura de seus títulos e resumos. Em seguida, procedeu-se à leitura integral das publicações, analisadas segundo a metodologia proposta por Dresch, Lacerda e Antunes Júnior (2015), na qual faz-se uma pré-avaliação da qualidade das publicações com os critérios de qualidade de execução do estudo, adequação à questão da revisão e adequação ao foco da revisão (Quadro 1).

Quadro 1- Critérios para avaliação das dimensões da qualidade dos estudos.

\begin{tabular}{|c|c|c|c|c|}
\hline Dimensão & Qualidade da execução do estudo & Adequação à questão da revisão & $\begin{array}{c}\text { Adequação ao foco da } \\
\text { revisão }\end{array}$ \\
\hline Alta & $\begin{array}{c}\text { Atende aos padrões demandados } \\
\text { para o tema em estudo. }\end{array}$ & $\begin{array}{c}\text { Abrange o objeto de estudo da } \\
\text { revisão sistemática. }\end{array}$ & $\begin{array}{c}\text { Apresenta conteúdos } \\
\text { imprescindíveis à revisão. }\end{array}$ \\
\hline Média & $\begin{array}{c}\text { Apresenta lacunas em relação aos } \\
\text { padrões demandados para o tema } \\
\text { em estudo. }\end{array}$ & $\begin{array}{c}\text { Abrange parcialmente o objeto de } \\
\text { estudo da revisão sistemática. }\end{array}$ & $\begin{array}{c}\text { Apresenta conteúdos } \\
\text { similares à revisão. }\end{array}$ \\
\hline Baixa & $\begin{array}{c}\text { Apresenta inconformidades em } \\
\text { relação aos padrões demandados } \\
\text { para o tema em estudo. }\end{array}$ & $\begin{array}{c}\text { Aborda superficialmente o objeto } \\
\text { de estudo da revisão sistemática. }\end{array}$ & $\begin{array}{c}\text { Apresenta conteúdos } \\
\text { distintos à revisão. }\end{array}$ \\
\hline
\end{tabular}

Fonte: Adaptado de Dresch, Lacerda e Antunes Júnior (2015).

Após a leitura dos trabalhos pré-selecionados e suas respectivas classificações nas dimensões da qualidade, estabeleceu-se a qualificação ponderada seguindo os critérios do Quadro 2, selecionando-se apenas as publicações com alta qualidade. 
Faeda, M. L. C.; Callejas, I. J. A; Influência do traçado e malha nos custos de implantação de loteamentos horizontais urbanos: uma revisão sistemática. ES - Engineering and Science, 2021, 10:3.

Quadro 2 - Critério de ponderação da qualidade das fontes para inclusão no estudo.

\begin{tabular}{|c|c|c|c|}
\hline $\begin{array}{c}\text { Qualidade da } \\
\text { Execução }\end{array}$ & $\begin{array}{c}\text { Adequação à questão da } \\
\text { revisão }\end{array}$ & $\begin{array}{c}\text { Adequação ao foco da } \\
\text { revisão }\end{array}$ & $\begin{array}{c}\text { Critério de qualidade } \\
\text { ponderada }\end{array}$ \\
\hline Alta & Alta & Alta & Alta \\
\hline Alta & Alta & Média & Alta \\
\hline Média & Alta & Alta & Alta \\
\hline Alta & Média & Média & Média \\
\hline Alta & Média & Média & Média \\
\hline Média & Média & Média & Baixa \\
\hline Média & Baixa & Baixa & Baixa \\
\hline Média & Baixa & Baixa & Baixa \\
\hline Média & Média & Baixa & Baixa \\
\hline Baixa & Baixa & Média & Baixa \\
\hline Baixa & Média & Baixa & \\
\hline Baixa & Média & Ala & Ana \\
\hline
\end{tabular}

Fonte: Adaptado de Dresch, Lacerda e Antunes Júnior (2015).

\section{RESULTADOS E DISCUSSÕES}

Foram encontradas 17 publicações por meio da busca com os descritores "custos", "urbanização", "forma urbana" nas bases de dados selecionadas (Quadro 3). Para a seleção, foi realizada uma análise individual das pesquisas, analisando os temas abordados e se o seu desenvolvimento contribuiria com a pergunta inicialmente estabelecida, o que resultou na seleção previa de dez trabalhos.

Quadro 3 - número de publicações encontradas por base de dados pesquisada.

\begin{tabular}{|l|l|}
\hline \multicolumn{1}{|c|}{ Base de dados } & \multicolumn{1}{|c|}{ "custos", "urbanização", "forma urbana" } \\
\hline Capes & 2 artigos \\
\hline Google Acadêmico & 11 artigos \\
\hline Scielo & 4 artigos \\
\hline
\end{tabular}

Refinou-se a busca a partir de trabalhos que se relacionavam diretamente com custos de urbanização, selecionando-se aqueles com classificação alta de qualidade ponderada, o que resultou ao final em seis publicações (Quadro 4). Os trabalhos selecionados foram os mais abrangentes em relação ao tema da revisão sistemática em questão.

\begin{tabular}{|l|l|l|l|l|}
\multicolumn{1}{|c|}{ Quadro 4-Artigos de alta qualidade ponderada selecionados para a revisão sistemática. } \\
\hline \multicolumn{1}{|c|}{ Autor(es) } & \multicolumn{1}{|c|}{ Tipo } & Local da pesquisa & Selecionado & \multicolumn{1}{c|}{ Título } \\
\hline $\begin{array}{l}\text { Mascaró } \\
(1979)\end{array}$ & Tese & São Paulo - SP & Sim & $\begin{array}{l}\text { Custos de infraestrutura: Um } \\
\text { ponto de partida para o desenho } \\
\text { econômico urbano }\end{array}$ \\
\hline $\begin{array}{l}\text { Andrade } \\
(1983)\end{array}$ & Artigo & Rio de Janeiro - RJ & Não & $\begin{array}{l}\text { Custos de urbanização: os } \\
\text { enfoques financeiros, de } \\
\text { eficiência e de equidade social }\end{array}$ \\
\hline $\begin{array}{l}\text { Inouye } \\
\text { Souza (2004) }\end{array}$ & Artigo & São Paulo - SP & Sim & $\begin{array}{l}\text { A utilização de indicadores } \\
\text { físicos na discussão dos custos de } \\
\text { urbanização de conjuntos } \\
\text { habitacionais horizontais }\end{array}$ \\
\hline
\end{tabular}

Quadro 4 - Artigos de alta qualidade ponderada selecionados para a revisão sistemática (continuação). 
Faeda, M. L. C.; Callejas, I. J. A; Influência do traçado e malha nos custos de implantação de loteamentos horizontais urbanos: uma revisão sistemática. ES - Engineering and Science, 2021, 10:3.

\begin{tabular}{|c|c|c|c|c|}
\hline Autor(es) & Tipo & Local da pesquisa & Selecionado & Título \\
\hline $\begin{array}{l}\text { Abiko et al } \\
(2005)\end{array}$ & Artigo & $\begin{array}{l}\text { Washington, D.C - } \\
\text { EUA. }\end{array}$ & Sim & $\begin{array}{l}\text { Custos básicos de } \\
\text { empreendimentos de urbanização } \\
\text { de favelas no Brasil }\end{array}$ \\
\hline $\begin{array}{l}\text { Mancini } \\
(2008)\end{array}$ & Dissertação & Brasília - DF & Sim & $\begin{array}{l}\text { Avaliação dos custos da } \\
\text { urbanização dispersa no Distrito } \\
\text { Federal }\end{array}$ \\
\hline $\begin{array}{l}\text { Inouye } \\
(2009)\end{array}$ & Tese & São Paulo -S P & Sim & $\begin{array}{l}\text { Proposição de um método para } \\
\text { subsidiar o prognóstico de custos } \\
\text { de urbanização de conjuntos } \\
\text { habitacionais horizontais com } \\
\text { base em indicadores físicos }\end{array}$ \\
\hline $\begin{array}{l}\text { Wenban- } \\
\text { Smith (2011) }\end{array}$ & Artigo & Londres - RU & Não & $\begin{array}{l}\text { Influence of urban form on } \\
\text { spatial costs }\end{array}$ \\
\hline $\begin{array}{l}\text { Bezerra } \\
(2016)\end{array}$ & Artigo & Brasília - DF & Sim & $\begin{array}{l}\text { Avaliação do incremento de } \\
\text { custos de obras de urbanização } \\
\text { em áreas urbanas informais }\end{array}$ \\
\hline $\begin{array}{l}\text { Costa e Mello } \\
(2017)\end{array}$ & Artigo & Foz do Iguaçu - PR & Não & $\begin{array}{l}\text { Custo estimado para projetos } \\
\text { hipotéticos de urbanização e } \\
\text { infraestrutura básica de } \\
\text { loteamentos para avaliação de } \\
\text { glebas urbanas através do método } \\
\text { involutivo }\end{array}$ \\
\hline $\begin{array}{l}\text { Ferreira e } \\
\text { Nascimento } \\
(2019)\end{array}$ & Artigo & Xanxerê - SC & Não & $\begin{array}{l}\text { O custo da infraestrutura urbana: } \\
\text { um delineamento par o } \\
\text { desenvolvimento de pequenos } \\
\text { municípios }\end{array}$ \\
\hline
\end{tabular}

Durante a leitura e análise dos estudos selecionados procedeu-se a coleta e síntese dos dados para identificar quais os principais indicadores utilizados para diagnóstico de diferentes concepções urbanísticas (traçado e malha urbana) e sua influência/indução nos custos de infraestrutura das glebas. Em geral, as pesquisas possuem pontos relevantes de concordância em relação à influência do traçado e malha viária nos custos de infraestrutura. Outro fator de convergência é a indicação de que densidade populacional das glebas tem forte influência no tipo de traçado e malhas adotados. Segundo Cavalcanti e Souza (2000), os indicadores são uma maneira concreta de simplificar fenômenos complexos e abstratos de forma quantitativa ou qualitativa, uma vez que o uso excessivo de informações pode dificultar a tomada de decisão.

Mascaró (1979) buscou investigar a influência da forma do traçado e alguns fatores nos custos dos componentes do sistema de infraestrutura urbana. Os seguintes subsistemas foram considerados: rede de esgoto, rede de água, sistema de drenagem, e pavimentação. Fatores como tamanho, forma, densidade e declividade da gleba assim como o tipo de traçado da rede adotado foram correlacionados com os custos para implantação dos subsistemas pesquisados. $\mathrm{O}$ autor evidenciou que o tipo de traçado adotado interfere nos custos das redes, assim como a densidade da gleba. Porém, existem fatores com menor influencia nos custos dos subsistemas pesquisados como tamanho e forma. Isoladamente, em alguns subsistemas, alguns fatores apresentaram alta, pouca ou ainda insignificante contribuição nos custos dos componentes (Quadro 5). 
Faeda, M. L. C.; Callejas, I. J. A; Influência do traçado e malha nos custos de implantação de loteamentos horizontais urbanos: uma revisão sistemática. ES - Engineering and Science, 2021, 10:3.

Quadro 5 - Redes de infraestrutura urbana e fatores de influência nos custos.

\begin{tabular}{|l|c|c|c|c|c|}
\hline \multicolumn{1}{|c|}{ Rede } & $\begin{array}{c}\text { Tipo de } \\
\text { traçado da } \\
\text { rede }\end{array}$ & $\begin{array}{c}\text { Tamanho da } \\
\text { gleba }\end{array}$ & $\begin{array}{c}\text { Forma da } \\
\text { gleba }\end{array}$ & $\begin{array}{c}\text { Densidade da } \\
\text { gleba }\end{array}$ & $\begin{array}{c}\text { Declividade da } \\
\text { gleba }\end{array}$ \\
\hline Água & $\mathrm{A}$ & $\mathrm{B}$ & $\mathrm{C}$ & $\mathrm{A}$ & $(-)$ \\
\hline Esgoto & $\mathrm{A}$ & $\mathrm{C}$ & $(-)$ & $\mathrm{A}$ & $\mathrm{B}$ \\
\hline Drenagem & $(-)$ & $\mathrm{A}$ & $\mathrm{B}$ & $\mathrm{A}$ & $\mathrm{B}$ \\
\hline Pavimentação & $\mathrm{A}$ & $(-)$ & $(-)$ & $\mathrm{A}$ & $\mathrm{A}$ \\
\hline Elétrica/ iluminação & $\mathrm{A}$ & $\mathrm{C}$ & $(-)$ & $\mathrm{A}$ & $(-)$ \\
\hline
\end{tabular}

Legenda: A - alta influência; B - Média influência; C - Baixa influência e (-) insignificante/não-detectada/nãodetectada ou não conclusiva. Fonte: Mascaró (1979).

Especificamente quanto aos custos de pavimentação urbana de loteamentos horizontais, Mascaró (1979) buscou analisar a influência dos diferentes traçados urbanos por meio da métrica de porcentagem viária que estabelece a relação entre o total de vias que devem ser construídas em relação à área total da gleba atendida. Consideraram-se os seguintes traçados: os denominados de clássicos (onde não existe um condicionamento específico de tráfego) e os modernos, onde o planejamento do tráfego faz parte do projeto de pavimentação como meio de otimizar o fluxo com ruas principais e secundárias. A analise revelou que o menor tamanho das quadras repercute em maiores custos de pavimentação e que a adoção de estratégias de hierarquização de ruas e planejamento de acessos favorece a economia de malha viária e, consequentemente, nos custos de urbanização.

Mascaró (1979) também demonstrou que a adoção do tipo de traçado ortogonal de malha fechada, o mais comum na época, implica em um acréscimo no custo das redes da ordem de 20 a 30\%, em relação aos demais traçados analisados como, por exemplo, o traçado ortogonal em malha aberta, no qual existe uma rua principal e as demais são secundárias. Isso ocorre em virtude da economia das redes de infraestrutura devido à ocorrência de ruas sem saída e com frentes paralelas. Neste caso, as redes só precisam passar pelas vias secundárias, economizando o percurso na ordem de 40 a $50 \%$, e, consequentemente, reduzindo os custos na ordem de 30 a $40 \%$. O autor demonstra ainda que as redes mais afetadas pela escolha do traçado da malha viária são o sistema de abastecimento de água, rede de esgoto e pavimentação. No caso da rede de água, a escolha do traçado e a variação da quantidade de redes secundárias de abastecimento influem diretamente no custo final, sendo este fator mais relevante do que a própria densidade populacional da área estudada. Já para o sistema de esgotamento sanitário, o principal fator, em relação aos diferentes traçados que trazem grandes variações para os custos orçamentários, é a quantidade de ruas que a rede terá que percorrer para atender a todas as testadas, sendo assim a o traçado ortogonal de malha fechada é o mais custoso para a execução da urbanização da gleba. $\mathrm{O}$ autor apresenta a participação de cada rede nos custos totais de cada sistema de abastecimento em função da densidade habitacional usualmente expresso em habitantes por hectare (Quadro 6). 
Faeda, M. L. C.; Callejas, I. J. A; Influência do traçado e malha nos custos de implantação de loteamentos horizontais urbanos: uma revisão sistemática. ES - Engineering and Science, 2021, 10:3.

Quadro 6 - Participação de cada rede nos custos totais de cada sistema de abastecimento.

\begin{tabular}{|c|c|c|}
\hline \multirow{2}{*}{ Rede } & \multicolumn{2}{|c|}{ Participação total de cada rede no custo total das redes $(\%)$} \\
\cline { 2 - 3 } & Áreas de baixa densidade & Áreas de alta densidade \\
\hline Pavimento & 41,38 & 44,35 \\
\hline Drenagens pluviais & 14,38 & 15,65 \\
\hline Abastecimento de água & 3,93 & 3,50 \\
\hline Esgoto sanitário & 17,10 & 19,73 \\
\hline Abastecimento de gás encanado & 9,09 & 8,79 \\
\hline Abastecimento de energia elétrica & 13,16 & 6,81 \\
\hline Iluminação pública & 0,96 & 1,17 \\
\hline
\end{tabular}

Fonte: Mascaró, 1979.

Abiko et al. (2005) adaptaram os custos elaborado pela Revista Construção Mercado (2003) com vista a analisar a indecência de cada um dos subsistema no custo total de implantação de infraestrutura urbana de loteamentos (Quadro 7). Apesar das diferenças percentuais, nota-se que os maiores percentagens de custos se referem à implantação do subsistema viário, de esgotamento sanitário e de drenagem urbana, assim como ocorre nos quantificados por Mascaró (1979).

Quadro 7 - Custo de infraestrutura para glebas urbanizáveis (por hectare)

\begin{tabular}{|c|c|c|c|}
\hline Rede & $\begin{array}{c}\text { Custo por 10000m² de } \\
\text { gleba bruta, incluindo } \\
\text { BDI e projetos }\end{array}$ & $\begin{array}{c}\text { Custo/m² } \\
\text { gleba bruta }\end{array}$ & $\%$ \\
\hline Água & $2.208,10$ & 2,21 & 10,64 \\
\hline Esgoto & $4.121,29$ & 4,12 & 19,86 \\
\hline Drenagem & $2.073,36$ & 2,07 & 9,99 \\
\hline Pavimentação & $9.766,12$ & 9,77 & 47,07 \\
\hline $\begin{array}{c}\text { Energia elétrica/ } \\
\text { iluminação }\end{array}$ & 756,18 & 0,76 & 12,44 \\
\hline Total & $18.925,04$ & 18,93 & 100 \\
\hline
\end{tabular}

Fonte: Adaptado da Tabela “Avaliação de Glebas-Custo de Urbanização” (CONSTRUÇÃO MERCADO, 2003).

Em estudo mais recente, Costa e Mello (2017) avaliaram para projetos hipotéticos de loteamentos de glebas urbanas os custos de infraestrutura urbana básica por meio do método involutivo. A aplicação do método se fez a partir da utilização de procedimentos de levaram em consideração as normas aplicáveis a imóveis urbanos (avaliação dos loteamentos urbanos), consideração da legislação vigente quanto ao uso da terra e o reconhecimento de sua vizinhança. A elaboração de custos se deu a partir da composição orçamentaria baseada em dados derivados do Sistema EMOP (Empresa de Obras públicas do Estado do Rio de Janeiro) de custos unitários e do sistema PINI (Tabela de Composições de Preços para Orçamento TCPO elaborado pela Editora PINI ano base de 2012). A partir deste referencial, os autores elaboraram os custos de referência para a execução dos serviços básicos de implantação de empreendimentos urbanísticos horizontais, expresso na unidade de reais por $1.000 \mathrm{~m}^{2}$ de área de gleba a ser urbanizada. (Quadro 8). Os custos apresentados não contemplam o valor do BDI (Benefícios de Despesas Indiretas), uma vez que este é um valor variável, podendo ser aplicado sobre o valor total obtido para todos os serviços. Nesse estudo, nota-se variação entre os custos entre os subsistemas como ocorre nos levantamentos anteriormente apresentados, 
Faeda, M. L. C.; Callejas, I. J. A; Influência do traçado e malha nos custos de implantação de loteamentos horizontais urbanos: uma revisão sistemática. ES - Engineering and Science, 2021, 10:3.

com o subsistema de pavimentação urbana, esgotamento sanitário e de drenagem urbana também apresentando os maiores custos na composição.

Quadro 8 - Valores percentuais dos serviços de urbanização e infraestrutura básica (elaborado a partir tabela de composições de preços para orçamentos - TCPO/ PINI ano base de agosto de 2012)

\begin{tabular}{|c|c|c|}
\hline \multirow{2}{*}{ Serviços } & \multicolumn{2}{|c|}{ Valores PINI } \\
\hline & Valor $\left(R \$ / 1000 m^{2}\right.$ de área útil $)$ & Peso em porcentagem $(\%)$ \\
\hline Terraplenagem & $2.951,06$ & 7,05 \\
\hline Rede de água potável & $5.028,54$ & 12,02 \\
\hline Rede de esgoto & $10.962,87$ & 26,20 \\
\hline Drenagem - Galerias & $4.568,20$ & 10,92 \\
\hline Drenagem - Guias e sarjetas & $4.138,48$ & 9,89 \\
\hline Pavimentação & $12.344,76$ & 29,50 \\
\hline Rede de iluminação & $1.849,92$ & 4,42 \\
\hline Total & $41.843,83$ & 100,00 \\
\hline
\end{tabular}

Fonte: Adaptado pela autora.

A partir da analise dos estudos desenvolvidos por Mascaró (1979), Abiko et al. (2005) e Costa e Mello (2017), apesar da existência de uma certa discrepância de valores percentuais, nota-se que todos os estudos apontam a execução do sistema viário como o subsistema mais expressivo em termos de custos, seguido pelo custo de execução da rede de drenagem. Diante disso, percebe-se que o subsistema de pavimentação derivado a partir do sistema viário, possui forte influência no custo final da urbanização das glebas destinadas a loteamentos horizontais (Quadro 9). Nesse sentido, não só subsistema de pavimentação, mas os demais subsistemas ficam fortemente influenciados pelos traçados e malhas urbanas adotadas nos loteamentos horizontais uma vez que estes acompanham o sistema viário projetado.

Quadro 9 - Comparativo da participação dos custos dos subsistemas de infraestrutura no custo final

\begin{tabular}{|c|c|c|c|}
\hline \multirow{2}{*}{ Rede } & \multicolumn{3}{|c|}{ Participação da rede nos custos finais (\%) } \\
\cline { 2 - 4 } & Mascaró (1979) & Abiko e Azevedo (2005) & Costa e Mello (2017) \\
\hline Água & 3,93 & 12,02 & 10,64 \\
\hline Esgoto & 17,10 & 26,02 & 19,86 \\
\hline Drenagem & 14,38 & 20,81 & 9,99 \\
\hline Pavimentação & 41,38 & 29,5 & 47,07 \\
\hline Energia elétrica e iluminação & 13,16 & 4,42 & 12,44 \\
\hline
\end{tabular}

Ao se voltar o olhar para a questão dos indicadores, Inouye e Souza (2004) procuraram fornecer instrumentos para o diagnóstico de diferentes concepções urbanísticas quanto aos custos que induzem. Nesse sentido, sabendo-se da significativa importância do traçado e malha viária em relação aos custos de implantação, os autores buscaram identificar os principais indicadores que estão associados à escolha das concepções urbanísticas. A seleção destes se deu, entre outros aspectos, em função do forte impacto da extensão da malha viária sobre os demais elementos de urbanização. Nesse sentido, os seguintes indicadores físicos, estabelecidos a partir de expressões numéricas que indicam relações entre as quantidades das redes de infraestrutura e unidades vinculadas ao porte do empreendimento, 
foram considerados: Custo relativo à implantação do sistema viário por unidade habitacional; Custo unitário da calçada por área; área de calçada por metro linear; metro linear de calçada por metro linear de via interna à gleba; custo unitário do leito carroçável, área de leito carroçável por metro linear de via interna à gleba; e metros lineares de vias internas à área da gleba.

Entre os fatores pesquisados pelos autores, destacam-se o fator "vias internas", que está associado à área da gleba que serve diretamente às habitações, ou seja, quantifica o aproveitamento das vias externas para acessar os lotes. A título de comparação e utilizando-se de dois conjuntos habitacionais de mesma área, os autores verificaram que um dos conjuntos ilustrados na Figura 1 demandaram respectivamente 220 metros lineares de via (conjunto A) e 325 metros lineares de via (conjunto B), ocorrendo uma economia para a mesma área de lotes de 105 metros lineares de via (Figura 1), simplesmente pelo fato da possibilidade de aproveitamento das vias já existentes.

Figura 1 - Conjunto A - aproveitamento da via externa; Conjunto B - todos os acessos às unidades habitacionais internos à gleba

CONJUNTOA

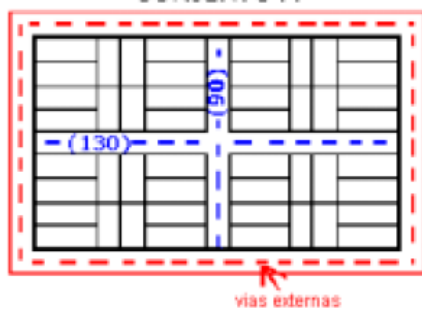

CONJUNTOO E

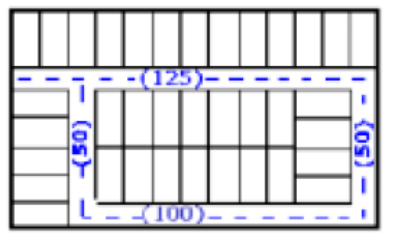

Fonte: Inouye e Souza, 2004

Outro fator analisado foi a "área das quadras", que se relaciona com o tamanho das quadras dos conjuntos habitacionais horizontais pesquisados, que no caso apresentavam o mesmo tamanho, com mesma quantidade e tamanho de lotes. Após a quantificação dos indicadores para cada uma das condições indicadas na Figura 2, estes revelaram um aumento de 2,8 metros lineares de via por unidade habitacional no conjunto $\mathrm{B}$, demonstrando que quando as glebas que apresentam maiores fragmentações por vias ocorre a elevação na quantidade de vias por unidade habitacional.

Figura 2 - Modelos de conjuntos habitacionais com tamanhos de quadras diferentes

CONJUNTOA

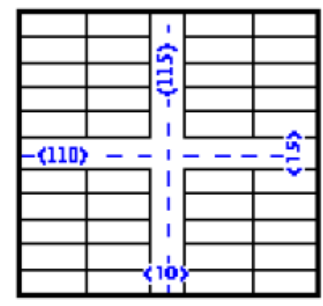

CONJUNTOE

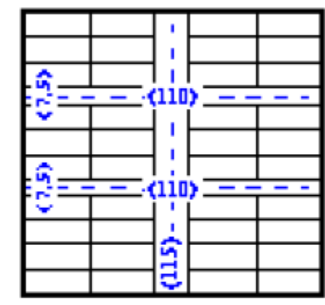

Fonte: Inouye e Souza, 2004. 
Outro indicador usado na pesquisa foi o da "compacidade das quadras internas", que é mensurado comparando-se a proximidade da forma da quadra à de um círculo com mesma área. Quanto mais esse fator se aproxima de 1, mais compacta a quadra se torna. Para as quadras indicadas na Figura 3, os autores constataram que as quadras mais fragmentadas demandaram $25 \%$ a mais de vias, uma vez que para as propostas urbanísticas dos Conjuntos A e $\mathrm{B}$, foram demandadas 200 e 250 metros de via, respectivamente.

Figura 3 - Modelo de conjuntos com quadras de mesma área, mas com formas diferentes

CONJINTOQ A

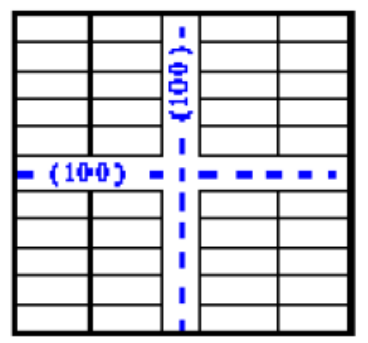

CONJUNTOB

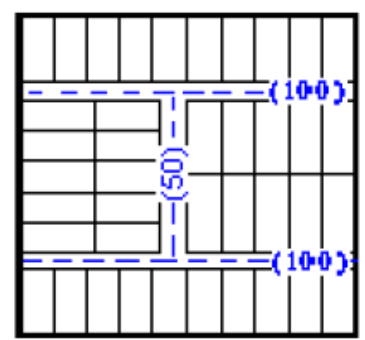

Fonte: Inouye e Souza, 2004.

A partir da análise dos indicadores apresentados, os autores demonstram que a redução da demanda por vias é um dos principais parâmetros a serem considerados na fase de projeto. Nesse sentido, os autores sugerem que a redução desse indicador pode ser conseguida a partir da adoção de algumas estratégias projetuais, tais como, posicionando-se as áreas não habitacionais contíguas ao meio externo (para a utilização das vias externas como meio de acesso) ou ainda contíguas às próprias áreas habitacionais, com acessos diretos através de caminhos ou áreas verdes, priorizando redução e compacidade das quadras, ou ainda adotando quadras habitacionais maiores e mais quadradas (em lugar de quadras alongadas e de pequena área), bem como a utilização de tipologias habitacionais com pequena testada e uso de vias externas para acessar parte das habitações.

Abiko e Azevedo (2005) desenvolveram um estudo acerca dos custos básicos de empreendimentos de urbanização de favelas no Brasil. Entretanto, para o desenvolvimento dos indicadores que influenciam os custos de urbanização de áreas informais, os autores estudaram os custos de infraestrutura em geral, incluindo as áreas urbanas formais, procurando identificar fatores que explicam seu comportamento. Os autores analisaram os custos das redes de abastecimento de água, energia elétrica e iluminação pública, esgotamento sanitário, drenagem e pavimentação. Os autores relatam que os fatores mais importantes no custo são em primeiro lugar o tipo de traçado das redes, sendo que neste, a influência do desenho do sistema viário é preponderante. Nesse sentido, os autores apresentam que o traçado ortogonal de malha fechada encarece as redes, em função do seu aumento muito significativo da quantidade de malha viária para o mesmo número de habitações atendidas. $\mathrm{O}$ outro fator importante é a densidade populacional, refletido por meio da disponibilização de uma maior quantidade de habitações atendidas em uma gleba. Isso se deve ao fato de que o incremento de população atendida, para a mesma área, leva a acréscimos pequenos no custo global da rede, sendo o custo das redes para 500 habitantes, por exemplo, pouco superior ao custo das redes para 50 habitantes, distribuídos na mesma área.

Os referidos autores ainda compararam os custos apresentados na Revista Construção Mercado (2003) (Quadro 7) com os apresentados por Mascaró (1979) (Quadro 6), e verificaram que as maiores discrepâncias são referentes às redes de abastecimento de água e elétrica, sendo a última justificável pelo fato dos custos do Quadro 7 incluírem somente iluminação pública. Os autores consideram que a variação dos custos das redes estudadas, por 
área urbanizada e por habitação, se dá em virtude do tipo de traçado da rede, função basicamente do desenho do sistema viário e, em menor escala, do traçado da própria rede, do tamanho da gleba urbanizada, da forma da gleba, da densidade da gleba e declividade da gleba.

Mancini (2008) analisou os custos de urbanização a partir de pesquisas bibliográficas sobre o tema, traçando uma análise comparativa para caso da urbanização do Distrito Federal, partindo da premissa de que o sistema viário e o sistema de drenagem são responsáveis por mais da metade dos custos de todo um conjunto de infraestrutura. Utilizando-se como referência a tabela de custos apresentada por Mascaró (1979) (Quadro 6), o autor verificou que pavimentação e drenagem têm uma participação entre 55 a $60 \%$ do custo total das redes, ou seja, o sistema viário é responsável por mais da metade do custo total para a implantação de loteamentos horizontais. O autor ressalta que os fatores mais importantes no custo são, em primeiro lugar, o tipo de traçado de rede, influenciado preponderantemente pelo do traçado viário, e a densidade de ocupação que influencia diretamente no custo por habitação atendida.

A principal observação feita por Mancini (2008) é que a estrutura urbana determinada pela malha viária influencia o tipo de traçado das redes de infraestrutura e, consequentemente, seus custos. Dessa forma, a adoção do desenho urbano em traçado ortogonal e malha fechada encarece as redes, em função de sua maior extensão, enquanto os traçados baseados em hierarquização viária, tomando-se como referência o modelo de traçado ortogonal em malha aberta, são mais econômicos, visto que levam à uma economia de redes através da otimização de suas capacidades, como, por exemplo, para a pavimentação. O autor não intencionou analisar os custos econômicos dos sistemas de infraestrutura, enquanto solução de engenharia, o que resultaria na definição de valores monetários, mas sim fornecer uma contribuição para as discussões a respeito da dispersão urbana, feitas a partir da inter-relação entre padrões morfológicos da urbanização dispersa e comportamento de custos de infraestrutura urbana.

Inouye (2009) analisou o processo de concepção e dimensionamento dos elementos de urbanização, bem como o método de prognóstico dos seus custos, para levantar os potenciais fatores influenciadores da variação dos custos de infraestrutura. Para isso, os conjuntos habitacionais foram organizados de acordo com o seu tipo de desenho urbano e os valores mínimos, medianos e máximos dos custos de infraestrutura. Os traçados analisados foram o traçado ortogonal de malha fechada e traçado ortogonal de malha aberta ou misto.

A autora, a partir do estudo bibliográfico e dos projetos, observou que os principais influenciadores na quantificação de malha viária foram a forma das quadras e suas áreas médias. Dessa forma, a autora se preocupou em estudar os traçados com formatos que levam a um perímetro menor para certa área a ser urbanizada. Concluiu que aqueles que se aproximam do formato circular, uma vez que possuem melhor compacidade e seu perímetro não demanda sistema viário, reduzem o consumo de vias por $\mathrm{m}^{2}$, melhorando o aproveitável de gleba.

Segundo Inouye (2009), no conjunto de traçado ortogonal de malha aberta, as quadras possuem boa parte do seu perímetro limítrofe à gleba, o que contribui com o aproveitamento das vias externas para dar acesso às áreas habitacionais, diminuindo a necessidade de vias internas. Além disso, o seu desenho urbano favorece a união de áreas habitacionais, de lazer e institucionais em uma única quadra, diminuindo ainda mais a demanda por vias. Já no traçado ortogonal de malha fechada, o desenho urbano implica na necessidade de vias contornando quadras, aumentando em quase quatro vezes a metragem de vias para a mesma área da gleba.

No caso do sistema de drenagem superficial, por exemplo, seus custos variam diretamente com a metragem de vias, sendo concordante com as considerações feitas para os 
custos da pavimentação. Já para a drenagem subterrânea, considerou-se os principais indicadores como sendo o tamanho e relevo da gleba, densidade habitacional, desenho urbano e tipo de concepção da rede. Para a rede de esgoto, utilizando o parâmetro de quantidade de metros de rede pela metragem das vias, concluiu-se que os traçados ortogonais de malhas fechadas ou mistos favorecem a economia de rede quando comparado com o sistema ortogonal de malha aberta, visto que na rede perpendicular há uma tendência de acréscimo de tubulações que passam em áreas públicas que não fazem parte do sistema viário quando os culs-de-sac estão nos pontos baixos do terreno. Já para a rede de água, o fator que mais influência no custo é o traçado da própria rede, que pode ser independente do desenho urbano, visto que a rede em leque, tida como mais econômica, pode ser executada no formato em malha, misto e ramificado.

Segundo Inouye (2009), os valores de referência gerados para os indicadores propostos poderão subsidiar discussões sobre a concepção do desenho urbano, como, por exemplo, quando se responde a questões quanto ao tipo de traçado a se adotar um parcelamento do solo visando favorecer a máxima compacidade e área média das quadras, pode-se obter a proporção de 1,0 metro de viário para $100 \mathrm{~m}^{2}$ de gleba aproveitável; em contrapartida, ao se favoreceremos valores mínimos obtidos para estes indicadores (compacidade e área média), tem-se a necessidade de um comprimento viário três vezes maior.

No Quadro 10 é apresentada uma síntese dos principais indicadores utilizados nas pesquisas que orientaram este estudo. A quantificação desses indicadores permite a materialização dos impactos das combinações dos diferentes tipos de traçados e malhas que são passíveis de serem adotados pelos projetistas para a urbanização de uma gleba, bem como sua relação com o aproveitamento da gleba, permitindo ainda uma aferição indireta preliminar dos possíveis custos orçamentários inerentes a uma possível implantação.

Quadro 10 - Indicadores identificados na pesquisa de revisão sistemática.

\begin{tabular}{|c|c|}
\hline Indicador & Fórmula correspondente \\
\hline Lotes por hectare & Lotes $/$ ha $=\frac{\text { Número total de lotes }}{\text { Área da gleba em hectares }}$ \\
\hline Área viária & Área viária $=\Sigma$ Área pavimentada de todo o lotemaneto \\
\hline Porcentagem viária & PV $\%=\frac{\text { Áreaviária }}{\text { Área útil para urbanização }}$ \\
\hline Extensão viária & Extensão viária $=\Sigma$ Metragem linear de todas as ruas pavimentadas $/ \mathrm{km}=\frac{\text { Númerototal de lotes }}{\text { Extensãoviária }}$ \\
\hline $\begin{array}{c}\text { Número de lotes/km } \\
\text { Fator de compacidade } \\
\text { das quadras }\end{array}$ & Fcompacidade quadras $=\frac{2 x \sqrt{3,14 x \text { Área } \text { quadra }}}{\text { Perímetro da quadra }}$ \\
\hline $\begin{array}{c}\text { Área média das quadras } \\
\text { Porcentagem total da } \\
\text { área loteada }\end{array}$ & Amédiaquadras $=\frac{\Sigma \text { Áreas das quadras }}{\text { Número total de quadras }}$ \\
\hline $\begin{array}{c}\text { Área viária consumida } \\
\text { por unidade de lote }\end{array}$ & Área loteada $(\%)=\frac{\text { Área destinada aos lotes }}{\text { Área total da gleba }}$ \\
\hline $\begin{array}{c}\text { Densidade } \\
\text { unidade de lote }\end{array}$ & Área viária/lote $=\frac{\text { Área viária }}{\text { Numero de lotes }}$ \\
\hline $\begin{array}{c}\text { Consumo de rede por } \\
\text { Densidade }=\frac{\text { Número total de habitantes }}{\text { Área do loteamento }}\end{array}$ \\
\hline
\end{tabular}


Faeda, M. L. C.; Callejas, I. J. A; Influência do traçado e malha nos custos de implantação de loteamentos horizontais urbanos: uma revisão sistemática. ES - Engineering and Science, 2021, 10:3.

\section{CONSIDERAÇÕES FINAIS}

Por meio da análise dos trabalhos selecionados, é possível concluir que a questão da escolha do traçado e malha viária é um importante fator que influencia os custos de infraestrutura. Notou-se concordância entre as pesquisas de que a porcentagem de malha viária é um dos principais fatores que influenciam a elevação dos custos, visto que os demais subsistemas de infraestrutura, em geral, guardam estreita relação com o traçado e malha definido para as vias pavimentadas, ou ainda com o seu entorno. Dessa forma, a otimização da urbanização e o planejamento das cidades passa pela escolha adequada do traçado e malha urbana e sua relação a topografia local, sendo que é sempre preferível a utilização de traçados ortogonais de malha aberta em detrimento do traçado ortogonal de malha fechada. Ressalta-se que a ortogonalidade do traçado não é fácil de ser conseguida, uma vez que esta guarda estreita relação com a topografia do local de urbanização, o que acarreta acréscimo de custos de infraestrutura. Para uma analise preliminar dos impactos que os diferentes traçados e malhas podem ocasionar durante o processo de concepção do desenho urbano, recomenda-se a quantificação dos indicadores apresentados nessa pesquisa como um guia orientativo das tomadas de decisões por parte dos projetistas urbanistas.

\section{REFERÊNCIAS}

ABIKO, A. K.; CARDOSO, L. R. de A.; RINALDELLI, R.; HAGA, H. C. R. Custos básicos de empreendimentos de urbanização de favelas no Brasil. Anais.. Washington, D.C.: The World Bank, 2005. p. 34-46.

ANDRADE, T.A. Cursos de urbanização: os enfoques financeiro, de eficiência e de equidade social. R. Brás. Econ., Rio de Janeiro, v. 37, n. 2, p. 131-143, abr./jun 1983.

BEM-JOSEPH, E. The future of Standards and Rules In Shaping Place: Reengineering the Urban Genetic Code. ASCE Journal of Urban Planning and Development, 2004. P. 6774 .

BEZERRA, Maria do Carmo de Lima. Avaliação do incremento de custos de obras de urbanização em áreas urbanas informais. PARC Pesquisa em Arquitetura e Construção, Campinas, SP, v. 7, n. 1, p. 12-22, jul. 2016.

BRASIL. Lei $\mathbf{n}^{0}$ 6.766. Dispõe sobre o parcelamento do solo urbano (modificada pela Lei9785/99). Brasília, $1979 . \quad$ Disponível em:<https://www25.senado.leg.br/web/atividade/materias/-materia/143752>.Acesso em: 26out. 2020.

CASTElNOU, A. Teoria do Urbanismo. Tese de doutorado em Meio Ambiente e Desenvolvimento - UFPR, 2007. 519p.

CAVALCANTI, A.R.; SOUZA, F.A.M. Indicadores urbanos para o desenvolvimento sustentável: o caso do litoral Norte de Maceió. In: ENCONTRO NACIONAL DE TECNOLOGIA DO AMBIENTE CONSTRUÍDO, 8., 2000,Salvador. Anais. Salvador: ANTAC, 2000.

CONSTRUÇÃO E MERCADO. Tabela de avaliação de Glebas: Custos de Infraestrutura. São Paulo: Editora Pini, v. 22, julho 2003.

CONSTRUÇÃO E MERCADO. Tabela de avaliação de Glebas: Custos de Infraestrutura. São Paulo: Editora Pini, v. 182, julho 2016, Mensal. 
Faeda, M. L. C.; Callejas, I. J. A; Influência do traçado e malha nos custos de implantação de loteamentos horizontais urbanos: uma revisão sistemática. ES - Engineering and Science, 2021, 10:3.

COSTA. V. R. A imaginação urbanística nos projetos e parcelamento do solo na cidade de Maceió 1945-1980. UM, Maceió, n. 27, p. 75-85, 2006.

COSTA. C. M. G; MELLO. I. P. Custo estimado para projetos hipotéticos de urbanização e infraestrutura básica de loteamentos para avaliação de glebas urbanas através do método involutivo. In: XIX COBREAP, Foz do Iguaçu-PR., p. 16, 2017.

DE SOUSA, M. R.; Ribeiro, A. L. P. Revisão sistemática e meta-análise de estudos de diagnóstico e prognóstico: um tutorial. Arq. Bras. Cardiol.,v.92 n.3, 2009.

DIAS, Paulo Roberto V. Engenharia de Custos - uma metodologia de orçamentação para obras civis. 5. Edição. São Paulo: Editora PINI. 2005.

DRESCH, A., LACERDA, D. P., ANTUNES JÚNIOR, J. Design Science Research: método de pesquisa para avanço da ciência e tecnologia. São Paulo: Bookman Editora, 2015. FERRARI, C. Dicionário de urbanismo. Disal Editora, São Paulo (2004).

ELOY, E. J. S.; CARDOSO, L. R. A. Parâmetros e conceitos dos custos de infraestrutura em uma cidade média. São Paulo: EPUSP, 2011. 15 p.

FERREIRA, A. S.; NASCIMENTO, D. R.. O custo da infraestrutura urbana: um delineamento para o desenvolvimento de pequenos municípios. Engineering Sciences, v.8, n.1, p.67-79, 2020.

GUILHERME MARTINS. Guilherme Martins Engenharia de Avaliações, 2021. Página inicial. Disponível em: 〈http://www.guilhermemartins.com.br >. Acesso em: 18 de maio de 2021.

INOUYE. K. P. Proposição de um método para subsidiar o prognóstico de custos de urbanização de conjuntos habitacionais horizontais com base em indicadores físicos. Tese de doutorado - Escola politécnica da Universidade de São Paulo. São Paulo, SP, p. 313, 2009.

INOUYE. K. P.; SOUZA. U. E. L. A utilização de indicadores físicos na discussão dos custos de urbanização de conjuntos habitacionais horizontais. Revista Ambiente Construído, Porto Alegre, v. 4, n. 1, p. 79-911, jan./mar 2004.

MANCINI. G. A. Avaliação dos custos de urbanização dispersa do Distrito Federal. Dissertação de mestrado no Programa de Pós Graduação (obtenção de título de mestre em planejamento urbano) - Faculdade de arquitetura e urbanismo da cidade de Brasília, Brasília, DF, p.167, 2008.

MASCARÓ. J. L. Custos de Infraestrutura: Um ponto de partida para o desenho econômico urbano. Tese apresentada à Congregação de Faculdade de Arquitetura e Urbanismo para concurso de Livre-docência, São Paulo, SP, p. 281, 1979.

MASCARÓ. J. L; Loteamentos urbanos. 2a edição. Porto Alegre: Masquatro Editora, 2005. $210 \mathrm{p}$.

MASCARÓ. J. L; YOSHINAGA. M. Infraestrutura urbana. 3. ed. Porto Alegre: Masquatro Editora, 2017. 208 p.

SAMPAIO, R.F; MANCINI, M.C. Estudos de revisão sistemática: um guia para síntese criteriosa da evidência científica. Rev. bras. fisioter., v.11, n.1, 2007. 
Faeda, M. L. C.; Callejas, I. J. A; Influência do traçado e malha nos custos de implantação de loteamentos horizontais urbanos: uma revisão sistemática. ES - Engineering and Science, 2021, 10:3.

WENBAN-SMITH, H. B. The influence of urban form on spatial costs. Recherches économiques de Louvain, Londres, RU, v. 77, p 23-46. 2011/2.

ZMITROWICS, W.; ANGELIS NETO, G. Infra-estrutura urbana. São Paulo: EPUSP, 1997. 